\title{
SISTEM PENDUKUNG KEPUTUSAN \\ TENDER PROYEK INFRASTRUKTUR JARINGAN KOMPUTER UPTD SMA 3 TEGAL DENGAN METODE BENEFIT COST RATIO (BCR)
}

\author{
Haries Anom Susetyo Aji Nugroho \\ Fakultas MTI, Program Studi S2 Teknik Informatika \\ Universitas AMIKOM Yogyakarta \\ Email: anom.haries@gmail.com \\ Khoirul Mustofa \\ Fakultas MTI, Program Studi S2 Teknik Informatika \\ Universitas AMIKOM Yogyakarta \\ Email: mustofa.khoirul26@gmail.com
}

\begin{abstract}
ABSTRAK
Proses pengadaan infrastruktur jaringan komputer adalah salah satu aspek terpenting bagi UPTD SMA 3 Tegal dalam proses bisnis yang dijalankan. Salah satu cara dalam proses pengadaan tersebut adalah dengan tender proyek. Tender proyek bertujuan mengefisiensi anggaran belanja sekolah UPTD SMA 3 Tegal. Setiap perusahaan akan mengajukan proposal mereka dengan kelebihan dari harga dan keuntungannya masing-masing. Untuk mempermudah proses tender yang berlangsung diperlukan sebuah alat bantu yaitu sistem pendukung keputusan. Pada sistem ini menggunakan metode Benefit Cost Ratio (BCR). Data tender yang dimasukkan pada sistem ini yaitu data perusahaan, alamat perusahaan tender, nama pemilik, jenis tender, harga penawaran peserta tender dan dokumen-dokumen lain yang sudah diverifikasi oleh admin dari sistem pengambilan keputusan ini. Output dari sistem pendukung keputusan adalah nama perusahaan yang memenangkan tender infrastruktur jaringan dengan dasar metode Benefit Cost Ratio (BCR) yang sudah diaplikasikan kedalam sistem pendukung keputusan tersebut.
\end{abstract}

Kata Kunci : Koputer, Jaringan, DSS, BCR, Tender, Infrastruktur.

\begin{abstract}
Procurement process of computer network infrastructure is one of the critical aspects for bussiness process UPTD SMA 3 Tegal. Way of the procuremen process is by project tender. Aim of project tender is budget efficiency UPTD SMA 3 Tegal. One of company will submit a proposal with the excess of the price and profit of them. For make it easier then a tool is needed, it is Decision Support System (DSS) by method a Benefit Cost Ratio (BCR). File of tender entered on this system is file of company, company address, owner name, type of tender, bid price and many more documents have been verified by admin of this decision support system. Output from this decision support system is acompany's name of the winner of the tender of computer network infrastructure base on benefit cost ratio (BCR) method that has been applied to desicion support system.
\end{abstract}

Keywords: Computer, Network, DSS, BCR, Tender, Infrastructure. 


\section{PENDAHULUAN}

UPTD SMA 3 Tegal adalah sebuah lembaga pendidikan menengah atas yang terletak di kota Tegal yang dalam proses bisnisnya sudah memanfaatkan teknologi informasi. Dalam rangka menjawab arahan dari pemerintah yang sekarang menuju kepada berbasis TI dalam segala proses bisnis yang terjadi maka diperlukan infrastruktur jaringan yang bagus.

Infrastruktur Jaringan yang bagus membutuhkan dana yang tidak kecil nilainya dan disamping itu anggaran pembelanjaan sekolah sangatlah kurang jika digunakan tanpa adanya manajemen. Saat ini pihak sekolah jika ada perusahaan yang mengajukan proposal maka pihak sekolah akan memilah mana yang paling efisien dan menguntungkan bagi sekolah dengan cara bertemu dan berdiskusi dengan perusahaan tersebut. Ketika belum cocok maka pihak sekolah akan mencari perusahaan lain yang mau bekerjasama sampai mendapatkan perusahaan yang memenuhi kebutuhan pihak sekolah.

Proses tersebut membutuhkan waktu yang sangatlah lama bahkan bisa sampai bermingguminggu lamanya. Dan proses tersebut tidaklah efektif dan efisien. Sehingga akan mengganggu berjalannya kegiatan di UPTD SMA 3 Tegal.

Melihat hal tersebut maka rencana penelitian yang akan dilaksanakan yaitu memasukkan unsur TI kedalam proses bisnis pemilihan tender pada UPTD SMA 3 Tegal. Yaitu dengan mengaplikasikan kedalam sebuah sistem pendukung keputusan (SPK). SPK sendiri memiliki tujuan yaitu memberikan informasi-informasi yang mendukung keputusan dari seorang user atau organisasi dalam memilih keputusan yang terbaik untuk dilakukan user ataupun organisasi.

Menurut Kusrini, sistem pendukung keputusan merupakan sistem informasi interaktif yang menyediakan informasi, pemodelan dan manipulasi data. Sistem itu digunakan untuk membantu pengambilan keputusan dalam situasi yang semi terstruktlur dan situasi tidak terstruktur, dimana tak seorang pun tahu secara pasti bagaimana keputusan seharusnya dibuat. ${ }^{[1]}$

Sedangkan menutur Setyaningsih, SPK adalah suatu sistem informasi yang spesifik yang ditunjukan untuk membantu manajemen dalam menggambil keputusan yang berkaitan dengan persoalan yang bersifat semi terstukrur secara efektif dan efisien, serta tidak menggantikan fungsi pengambil keputusan dalam membuat keputusan. ${ }^{[2]}$

Sedangkan untuk metode yang akan digunakan pada SPK yang akan dirancang adalah dengan menggunakan metode Benefit Cost Ratio (BCR). Metode tersebut diciptakan memang khusus untuk menentukan keuntungan atau kerugian dari sebuah investasi. Metod BCR menekankan pada perbandingan antara aspek manfaat (benefit) yang akan diperoleh dengan aspek biaya dan kerugian yang akan ditanggung $(\cos t) .{ }^{[3]}$

Salah satu rujukan pada penelitian ini adalah jurnal yang dibuat oleh Rukmana dengan judul Sistem Pendukung Keputusan Tender Proyek Menggunakan Metode BCR. Jurnal tersebut meneliti tentan kelayakan sebuah tender komponen peralatan yang akan dibeli oleh perusahaan PLN, yaitu apakah komponen tersebut layak dibeli oleh perusahaan atau tidak. Jurnal menjelaskan point-point yang lebih ke hal teknis perancangan SPK dengan metode BCR. ${ }^{[4]}$

Sedangkan penelitian yang akan dilaksanakan yaitu lebih kepada menggabungkan beberapa perusahaan tender yang sudah terverifikasi oleh admin dan hasil yang akan dikeluarkan oleh sistem pendukung keputusan ini adalah tender perusahaan mana yang paling menguntungkan untuk dipilih juga pendetailan dari rumus metode BCR dan implementasinya pada bahasa pemrograman untuk mempermudah penelitian-penelitian lain yang akan menggambil metode yang sama dikarenakan rumus BCR sendiri agak sulit dipahami.

Sistem pendukung keputusan dengan metode BCR ini diharapkan akan membantu UPTD SMA 3 Tegal dalam memilih perusahaan mana yang paling menguntungkan bagi sekolah tersebut. Dengan sistem ini nantinya sekolah membuat lelang tender dan melakukan verifikasi tender dan memasukkan semua informasi tender yang dibutuhkan dan memprosesnya didalam sistem pendukung keputusan tersebut. 


\section{METODOLOGI PENELITIAN}

Pada penelitian pembuatan sistem pendukung keputusan ini menggunakan metode System Development Life Cycle (SDLC) lebih fokus dengan menggambil Waterfall Model.

System Development Life Cycle (SDLC) adalah sebuah metodologi umum yang sering digunakan untuk mengembangkan sistem informasi. SDLC terdiri dari beberapa fase yang dimulai dari fase perencanaan, analisis, perancangan, implementasi dan pemeliharaan.

Sedangkan Waterfall Model adalah proses pengembangan perangkat lunak tradisional yang umum digunakan dalam proyek-proyek perangkat lunak. Metode ini adalah metode dengan pendekatan sistematis dan berurutan yang diawali dari identifikasi kebutuhan kemudian masuk ke proses analisis, pendisainan, pengkodingan, pengujian dan perawatan.

Tahapan yang dilaksanakan pada proses perancangan sistem pendukung pengambilan keputusan tender proyek infrastruktur jaringan UPTD SMA 3 Tegal yaitu sebagai berikut.

\subsection{Identifikasi kebutuhan}

Tahapan ini yaitu tahapan mengidentifikasi kebutuhan yang diperlukan oleh UPTD SMA 3 Tegal terhadap kebutuhan tender proyek infrastruktur jaringan komputer.

\subsection{Analisis kebutuhan}

Setelah mengidentifikasi kebutuhan yang diperlukan kemudian data yang diperoleh dianalisis sesuai kebutuhan sistem pendukung keputusan yang akan dirancang.

\subsection{Pendesainan sistem}

Tahapan ini yaitu merancang desain dari alur kerja sistem pendukung keputusan dengan Data Flow Diagram (DFD) kemudian membuat rancangan basis data yang diperlukan menggunakan Entity Relationship Diagram (ERD) setelah itu barulah merancang tampilan dari sistem tersebut menggunakan bahasa HTML dan CSS.

\subsection{Pengkodingan sistem}

Setelah tampilan sistem dirancang, kemudian dilaksanakan proses selanjutnya yaitu memasukkan koding-koding yang diperlukan dalam perancangan sistem tersebut menggunakan bahasa pemrograman PHP dengan basis data MariaDB.

\subsection{Pengujian}

Langkah selanjutnya adalah pengujian dari sistem pendukung keputusan yang sudah dirancang dengan cara mengentrikan semua data yang sudah di analisis pada tahapan sebelumnya dan memproses data tersebut sampai menghasilkan keputusan yang akan membantu UPTD SMA 3 Tegal dalam memilih tender perusahaan mana yang lebih memberikan keuntungan terhadap UPTD SMA 3 Tegal.

\subsection{Penerapan SPK dan pemeliharaan}

Setelah berhasil melaksanakan pengujian sistem pendukung keputusan maka langkah selanjutnya mengimplementasikan sistem pendukung keputusan pemilihan tender proyek infrastruktur jaringan komputer kepada UTPD SMA 3 Tegal dan melaksanakan pemeliharaan secara berkala agar sistem tersebut tetap optimal ketika dioperasikan.

\section{HASIL DAN PEMBAHASAN}

\subsection{Data Flow Diagram}

Data Flow Diagram merupakan suatu model logika data atau proses yang dibuat untuk menggambarkan darimana asal data dan kemana tujuan data yang keluar dari sistem, dimana data disimpan, proses apa yang menghasilkan data tersebut dan interaksi antara data yang tersimpan dan proses yang dikenakan pada data tersebut. ${ }^{[5]}$

Komponen dari DFD yang dipopulerkan oleh Demarco \& Hanif Al Fatta, yaitu Terminator / Entitas Luar (External Entity) atau Batas Sistem (Boundary), Proses, Data Store / Simpanan Data dan Alur Data. Berikut ini adalah desain DFD yang dirancang pada sistem pendukung keputusan 
pemilihan tender infrastruktur jaringan komputer UPTD SMA 3 Tegal yang akan dijelaskan berdasarkan gambar 1 DFD Level 0.

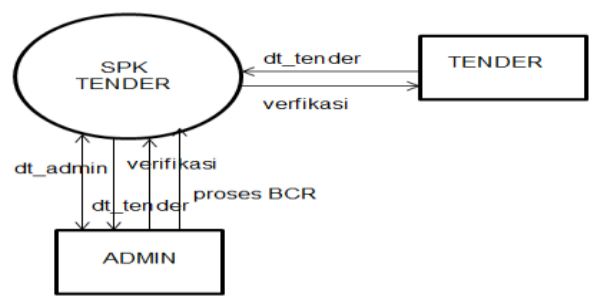

\section{Gambar 1 DFD Level 0}

Pada DFD diatas terdapat dua terminator yaitu terminator admin dan tender dan satu proses yaitu proses sistem pendukung keputusan yang dirancang kemudian terdapat beberapa alur data yaitu alur data tender, alur verifikasi, alur proses, alur data admin. Setelah DFD level 0 dirancang, maka proses selanjutnya dirincikan kembali pada DFD Level 1 yang rancangannya seperti pada gambar 2 DFD Level 1 dibawah ini.

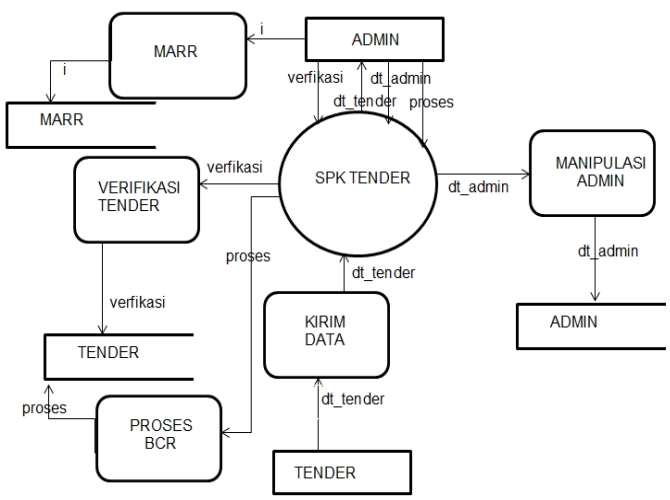

\section{Gambar 2 DFD Level 1}

Pada DFD Level 1 maka prosesnya lebih rinci lagi dan tergambar pula basis data yang terdapat pada sistem pendukung keputusan yang dirancang, seperti proses manipulasi data admin, proses input data tender, proses verifikasi tender, proses input MARR, dan proses lainnya. Selanjutnya adalah merancang tampilan basis data dengan menggunakan Entity Relationship Data (ERD). Menurut Sutanta, ERD Entity Relationship Diagram (ERD) merupakan suatu model data yang dikembangkan berdasarkan objek." Entity Relationship Diagram (ERD) digunakan untuk menjelaskan hubungan antar data dalam basis data kepada pengguna secara logis. ${ }^{6]}$

\subsection{Entity Relationship Diagram}

Entity Relationship Diagram (ERD) didasarkan pada suatu persepsi bahwa real world terdiri atas obyek-obyek dasar tersebut. Penggunaan Entity Relationship Diagram (ERD) relatif mudah dipahami, bahkan oleh para pengguna yang awam. Bagi perancang atau analis sistem, Entity Relationship Diagram (ERD) berguna untuk memodelkan sistem yang nantinya, basis data akan di kembangkan.

Model ini juga membantu perancang atau analis sistem pada saat melakukan analis dan perancangan basis data karena model ini dapat menunjukkan macam data yang dibutuhkan dan kerelasian antardata didalamnya. ${ }^{[6]}$ 
Perancangan ERD pada UPTD SMA 3 Tegal bisa dilihat pada gambar 3 ERD SPK BCR berikut ini.

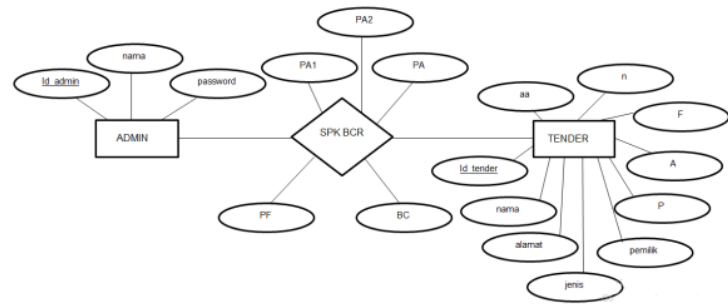

Gambar 3 ERD SPK BCR

\subsection{Input Data Admin dan Tender}

Pada proses input data admin yaitu menginputkan data nama dan password dari admin. Setelah itu melaksanakan input data tender yang sudah terverifikasi oleh admin UPTD SMA 3 Tegal. Data yang diinputkan adalah semua data yang sudah terpetakan pada diagram ERD diatas.

Tampilan proses input data tender yang sudah terverifikasi oleh admin UPTD SMA 3 Tegal bisa dilihat pada Gambar 4 Form Input Tender.

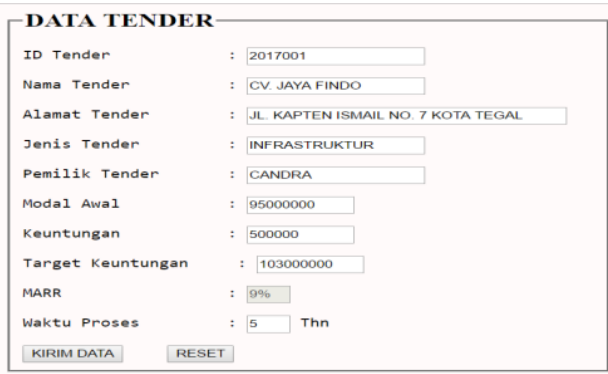

Gambar 4 Form Input Tender

Kemudian Hasil data dari tender yang telah dimasukkan kedalam aplikasi adalah berupa sebuah tabel yang menjelaskan semua rincian data-data tender. Tabel tersebut dapat dilihat pada Gambar 5 Tabel SPK dibawah ini.

\section{SISTEM PENDUKUNG KEPUTUSAN}

\section{PEMILIHAN TENDER INFRASTRUKTUR JARINGAN}

\begin{tabular}{|c|c|c|c|c|c|c|c|c|c|c|c|c|c|c|}
\hline $\begin{array}{c}\text { ID } \\
\text { TENDER }\end{array}$ & NAMA TENDER & ALAMAT TENDER & JENIS TENDER & PEMIUKK & $\begin{array}{l}\text { MODAL } \\
\text { AWAL }\end{array}$ & KEUNTUNGAN & $\begin{array}{c}\text { TARGET } \\
\text { KEUNTUNGAN }\end{array}$ & $\begin{array}{l}\text { WAKTU } \\
\text { TARGET }\end{array}$ & $\begin{array}{l}P / A \\
P / F\end{array}$ & $\mathrm{P} / \mathrm{A1}$ & P/A2 & $\mathrm{P} / \mathrm{A}$ & $\mathrm{P} / \mathrm{F}$ & $B C$ \\
\hline 2017001 & CV. JAYA FINDO & $\begin{array}{l}\text { JL. KAPTEN ISMAIL NO. } 7 \\
\text { KOTA TEGAL }\end{array}$ & INFRASTRUKTUR & CANDRA & 9500000 & 500000 & 1030000 & 5 & 1 & 0.0000 & 0.0000 & 0.0000 & 0.0000 & 0.0000 \\
\hline 2017002 & $\begin{array}{l}\text { CV. SURYA } \\
\text { KOMPUTER }\end{array}$ & JL. IALAK NO. 4 KOTA TEGAL & INFRASTRUKTUR & HERIANTO & 8000000 & 475000 & 9700000 & 5 & 1 & 0.0000 & 0.0000 & 0.0000 & 0.0000 & 0.0000 \\
\hline 2017003 & QV. SKI KOM & IL. SEPAT NO. 15 KOTA TEGAL & INFRASTRUKTUR & TEGUH & 8600000 & 450000 & 9100000 & 5 & 1 & 0.0000 & 0.0000 & 0.0000 & 0.0000 & 0.0000 \\
\hline
\end{tabular}




\section{Gambar 5 Tabel SPK}

\subsection{Pengkodingan SPK}

Langkah selanjutnya adalah proses pengkodingan. Proses ini menggunakan bahasa pemrograman HTML, CSS, PHP dan Mysql. HTML dan CSS lebih kepada desain program sedangkan PHP untuk pengoperasiannya dan Mysql sebagai basis datanya. $<$ ?php

Berikut ini contoh pengkodingan dengan menggunakan PHP dan Mysql.

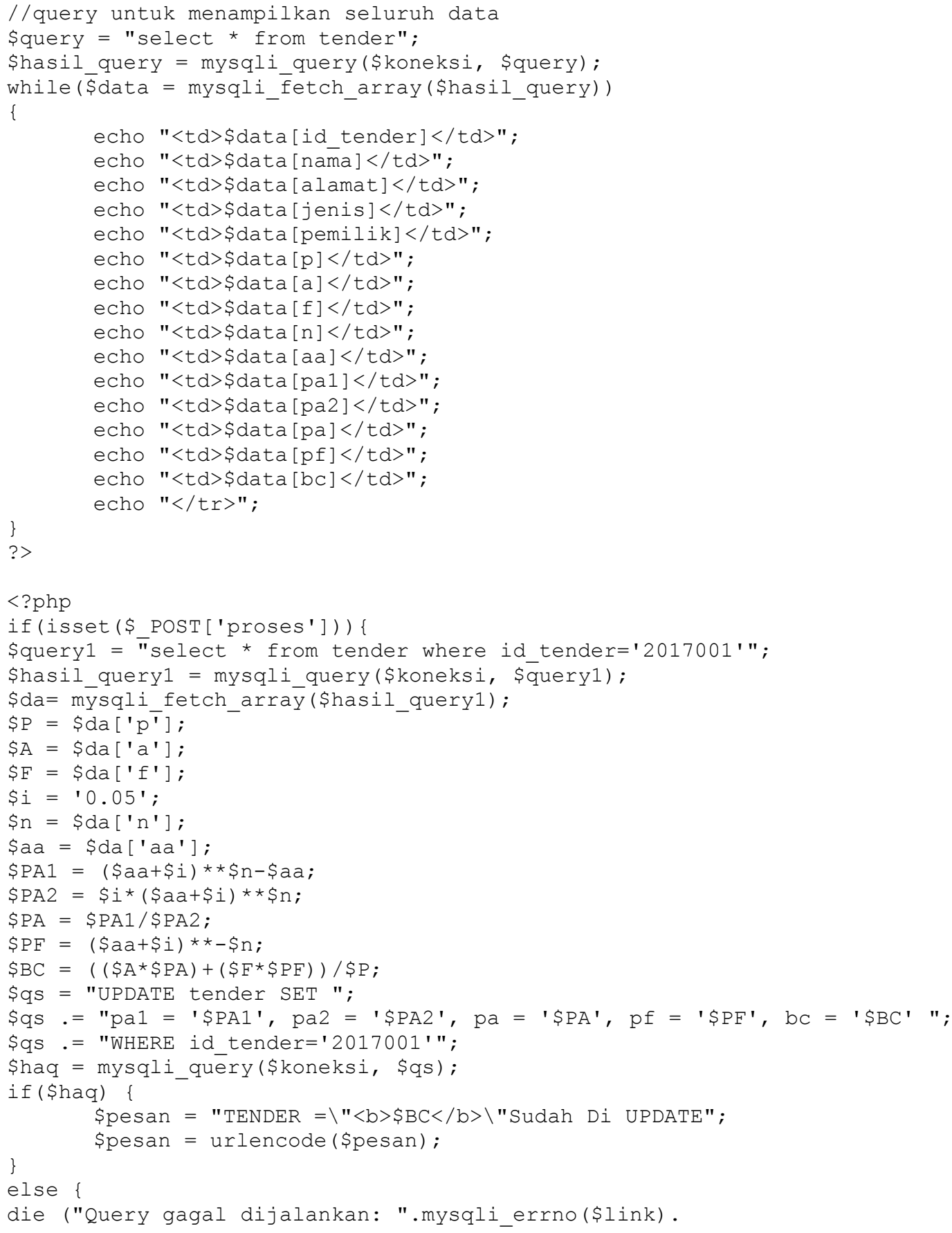




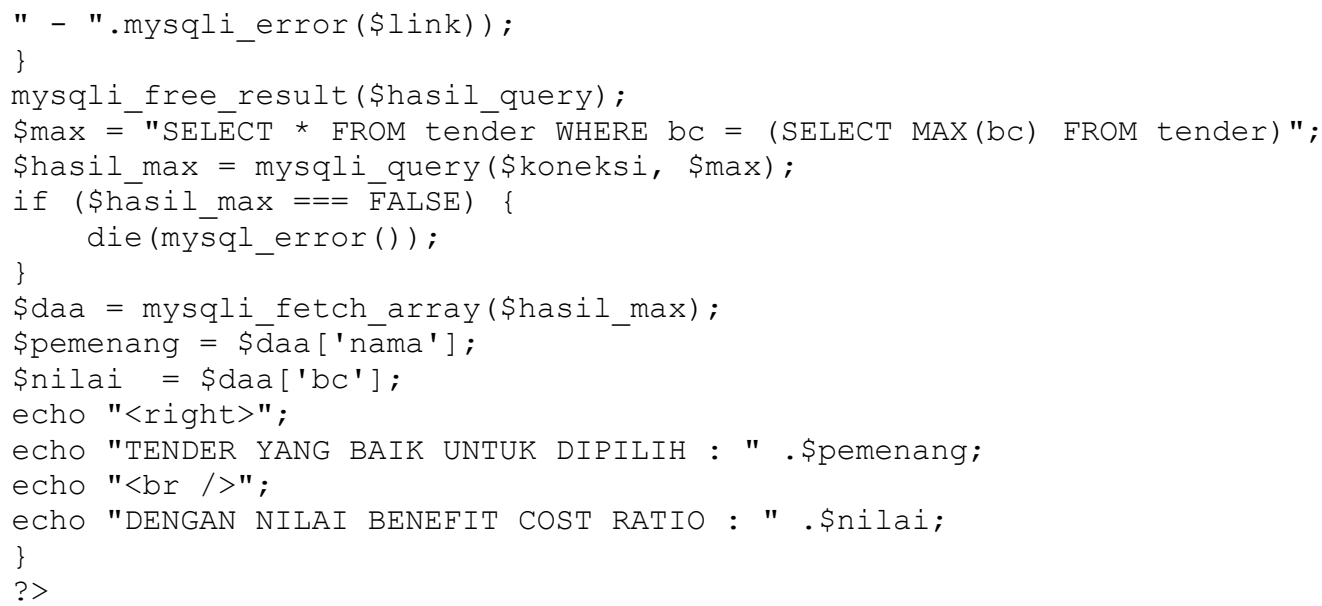

\subsection{Penghitungan BCR}

Setelah semua proses diatas sudah dijalankan, langkah terakhir adalah penghitungan BCR.

Rumus dari BCR adalah :

$$
\begin{aligned}
& B C R=\frac{\text { PV Benefit }}{\text { PV Cost }} \\
& B C R=\frac{(\text { A x PA })+(F \times P F)}{P} \\
& P A=\frac{(1+i)^{\mathrm{n}}-1}{i \times(1+i)^{\mathrm{n}}} \\
& P F=(1+i)^{-\mathrm{n}}
\end{aligned}
$$

Keterangan :

- Jika hasil $\mathrm{B} / \mathrm{C}<1$ maka manfaat dari proyek lebih kecil daripada biaya yang diperlukan secara ekonomi, proyek tersebut tidak layak untuk dijalankan

- Jika nilai BCR = 1 maka manfaat yang ditimbulkan proyek sama dengan biaya yang diperlukan secara ekonomi, proyek tersebut layak untuk dijalankan.

- Jika nilai BCR > 1 maka manfaat yang ditimbulkan proyek lebih besar dari biaya yang diperlukan secara ekonomi, proyek tersebut layak untuk dijalankan.

- P adalah Present Value / Nilai yang dimiliki.

- A adalah Keuntungan Tetap yang didapatkan.

- F adalah Future Value / Nilai (Keuntungan) yang akan didapatkan dimasa yang akan datang.

- $\mathrm{i}=$ adalah MARR yaitu tingkat suku bunga pengebalian minimum yang menarik.

- $\mathrm{n}$ adalah waktu proses proyek tersebut berlangsung. 
Setelah proses diatas diterapkan pada sistem pendukung keputusan, maka nilai B/C pada tabel data tender akan terisi. Berikut ini tampilan hasil pengolahan sistem pendukung keputusan tender proyek infrastruktur jaringan UPTD SMA 3 Tegal dengan metode BCR yang ditampilkan pada Gambar 6 Hasil Proses SPK.

\section{SISTEM PENDUKUNG KEPUTUSAN}

\section{PEMILIHAN TENDER INFRASTRUKTUR JARINGAN}

\begin{tabular}{|c|c|c|c|c|c|c|c|c|c|c|c|c|c|c|}
\hline $\begin{array}{l}\text { ID } \\
\text { TENDER }\end{array}$ & NAMA TENDER & ALAMAT TENDER & JENIS TENDER & PEMIUK & $\begin{array}{l}\text { MODAL } \\
\text { AWAL }\end{array}$ & KEUNTUNGAN & $\begin{array}{c}\text { TARGET } \\
\text { KEUNTUNGAN }\end{array}$ & $\begin{array}{l}\text { WAKTU } \\
\text { TARGET }\end{array}$ & $\begin{array}{l}P / A \\
P / F\end{array}$ & P/A1 & $P / A 2$ & $\mathrm{P} / \mathrm{A}$ & $\mathrm{P} / \mathrm{F}$ & $\mathrm{BC}$ \\
\hline 2017001 & CV. JAYA FINDO & $\begin{array}{l}\text { JL. KAPTEN ISMAIL NO. } 7 \\
\text { KOTA TEGAL }\end{array}$ & INFRASTRUKTUR & CANDRA & 9500000 & 500000 & 1030000 & 5 & 1 & 0.2763 & 0.0638 & 4.3295 & 0.7835 & 0.3128 \\
\hline 2017002 & $\begin{array}{c}\text { CV. SURYA } \\
\text { KOMPUTER }\end{array}$ & JL. JALAK NO. 4 KOTA TEGAL & INFRASTRUKTUR & HERIANTO & 8000000 & 475000 & 9700000 & 5 & 1 & 0.2763 & 0.0638 & 4.3295 & 0.7835 & 1.2071 \\
\hline 2017003 & CV. SKI KOM & JL. SEPAT NO. 15 KOTA TEGAL & INFRASTRUKTUR & TEGUH & 8600000 & 450000 & 9100000 & 5 & 1 & 0.2763 & 0.0638 & 4.3295 & 0.7835 & 1.0556 \\
\hline
\end{tabular}

\section{PROSES \\ TENDER YANG BAIK UNTUK DIPILIH: CV. SURYA KOMPUTER} DENGAN NILAI BENEFT COST RATIO : 1.2071

\section{Gambar 6 Hasil Proses SPK}

\section{KESIMPULAN}

Dari penelitian yang sudah dilaksanakan yaitu merancang sebuah sistem pendukung keputusan pemilihan tender proyek infrastruktur jaringan komputer pada UPTD SMA 3 Tegal mendapatkan kesimpulan bahwa sebuah sistem pendukung keputusan dapat diterapkan dengan berbagai metode dan model seperti penelitian ini menggunakan metode dari rumpun ilmu ekonomi yaitu Benefit Cost Ratio untuk mengetahui apakah investasi yang akan kita jalankan memberikan untung atau malah rugi.

Saran dari penelitian yang telah kerjakan adalah SPK yang dirancang masihlah sederhana dan perlu untuk ditingkatkan lagi dari berbagai sisi baik sisi desain maupun sisi penambahan metode dan lain sebagainya. Saran kepada objek penelitian adalah diharapkan SPK diterapkan bukan hanya pada pemilihan tender saja, akan tetapi dirancang SPK-SPK lain sesuai dengan proses bisnis yang berjalan pada UPTD SMA 3 Tegal.

\section{DAFTAR PUSTAKA}

[1] Kusrini, 2007. Konsep dan Aplikasi Sistem Pendukung Keputusan. .Yogyakarta : ANDI.

[2] Setyaningsih, W. 2015. Konsep Sistem Pendukung Keputusan. Malang : Yayasan Edelweis.

[3] Giatman, M. 2006. Ekonomi Teknik. Jakarta : PT. Raja Grafindo Persada.

[4] Rukmana, S., and Muslim, M. 2016. "Sistem Pendukung Keputusan Tender Proyek Menggunakan Metode Benefit Cost Ratio". Jurnal Sains dan Teknologi 5.

[5] Kristanto, A. 2008. Perancangan Sistem Informasi dan Aplikasinya. Yogyakarta : Gava Media.

[6] Sutanta, E. 2011. Basis Data dalam Tinjauan Konseptual. Yogyakarta : ANDI.

[7] Pratama, A. 2016. PHP Uncover Panduan Belajar PHP untuk Pemula. Padang Panjang : Dunia Ilkom.

[8] Pratama, A. 2016. HTML Uncover Panduan Belajar HTML untuk Pemula. Padang Panjang : Dunia Ilkom.

[9] Setyawan, B. 2016. "Studi Kelayakan Investasi Proyek Automasi Pabrik Kelapa Sawit di PT. XY". Jurnal PASTI 8. 1, 96-108

[10] Terryliani, V. 2013. "Sistem Pendukung Keputusan Pemilihan Benang Rajut Berdasarkan Hasil Rajutan Menggunakan Metode Benefit Cost Ratio (BCR) (Studi Kasus : Kokoro Shop Yogyakarta)". JAIS. 